\title{
Inclusão da Levedura de Cana-de-Açúcar (Saccharomyces cerevisiae) em Dietas para Frangos de Corte
}

\section{Márcio Glayton Araújo Grangeiro', Maria de Fátima Freire Fuentes ${ }^{2}$, Ednardo Rodrigues Freitas $^{3}$, Gastão Barreto Espíndola ${ }^{4}$, Francisco Militão de Souza ${ }^{5}$}

\begin{abstract}
RESUMO - Um experimento utilizando 672 pintos machos de um dia de idade, da linhagem AGROSS, foi conduzido com o objetivo de estudar o efeito da inclusão da levedura de cana-de-açúcar (Saccharomyces cerevisiae), proveniente da indústria de aguardente, em dietas para frangos de corte. As aves foram distribuídas em um delineamento inteiramente casualizado, constituído de seis tratamentos com 112 aves/tratamento, sendo oito repetições por tratamento com 14 aves cada. Os tratamentos constaram de seis dietas isoprotéicas (22 e $20 \%$ de proteína para as fases inicial e de engorda, respectivamente) e isocalóricas (3000 e $3150 \mathrm{kcal} \mathrm{EM/kg}$, para as fases inicial e de engorda, respectivamente) formuladas à base de milho e farelo de soja e com níveis crescentes de inclusão de levedura de cana-deaçúcar (LCA). Os tratamentos utilizados foram os seguintes: $\mathrm{T}_{1}=$ Dieta basal $(\mathrm{DB}) ; \mathrm{T}_{2}=\mathrm{DB}+1,5 \% \mathrm{LCA} ; \mathrm{T}_{3}=\mathrm{DB}+3,0 \% \mathrm{LCA}$; $\mathrm{T}_{4}=\mathrm{DB}+4,5 \% \mathrm{LCA} ; \mathrm{T}_{5}=\mathrm{DB}+6,0 \% \mathrm{LCA} ; \mathrm{T}_{6}=\mathrm{DB}+7,5 \% \mathrm{LCA}$, totalizando seis níveis de inclusão de levedura. Não foi verificada diferença significativa entre os tratamentos para as variáveis ganho de peso, consumo de ração, conversão alimentar, rendimento de carcaça, porcentagem de gordura abdominal e umidade da cama nas diferentes fases de criação das aves. Pode-se concluir que é possível a inclusão de até 7,5\% de LCA em dietas para frangos de corte, sem afetar o seu desempenho.
\end{abstract}

Palavras-chave: alimento alternativo, consumo de ração, conversão alimentar, ganho de peso

\section{Inclusion of Sugar Cane Yeast (Saccharomyces cerevisiae) in Broiler Chickens Diets}

\begin{abstract}
An experiment was carried out to evaluate the effect of the inclusion of sugar cane yeast (Saccharomyces cerevisiae), produced in the sugar cane distillery, in broiler chickens diets. Six hundred and seventy two one day old male broiler chicks, AGROSS line, were alloted to a completely randomized design with six treatments and one hundred and twelve birds per treatment, being eight replicates of fourteen birds per treatment. Treatments consisted of six isoproteic ( 22 and $20 \%$ of crude protein for initial and growing periods, respectively) and isocaloric (3000 and $3150 \mathrm{kcal} \mathrm{ME} / \mathrm{kg}$ for initial and growing periods, respectively) diets. These diets were formulated based on corn, soybean meal and different inclusion levels of yeast of sugar cane (YSC). The treatments were: $\mathrm{T}_{1}=\mathrm{Basal}$ Diet $(\mathrm{BD}) ; \mathrm{T}_{2}=\mathrm{BD}+1.5 \%$ YSC; $\mathrm{T}_{3}=\mathrm{BD}+3.0 \%$ YSC; $\mathrm{T}_{4}=\mathrm{BD}+4.5 \%$ YSC; $\mathrm{T}_{5}=\mathrm{BD}+6.0 \%$ YSC; $\mathrm{T}_{6}=\mathrm{BD}+7.5 \%$ YSC, resulting in six inclusion levels of YSC. Statistical analysis did not show any significant difference among the treatments for weight gain, feed intake, feed conversion, carcass yield, percentage of abdominal fat and moisture of the litter. According to the results, it can be concluded that it is possible the inclusion of up to $7.5 \%$ YSC in broiler diets without affecting their performance.
\end{abstract}

Key Words: alternative feed, feed intake, feed conversion, weight gain

\section{Introdução}

Em virtude da sazonalidade dos preços de produtos como o milho e o farelo de soja, ingredientes que mais contribuem para a elevação dos custos de produção de frangos de corte, tem havido crescente busca por alimentos "alternativos", principalmente os subprodutos agro-industriais, que são ingredientes de baixo custo e encontrados facilmente em certas regiões e em algumas épocas do ano. Entre estes ingredientes, encontram-se, segundo BUTOLO (1991), os produtos de origem microbiana como as leveduras, que são resíduos da indústria canavieira.

A levedura é utilizada nos processos de fermentação do caldo extraído da cana-de-açúcar, para que este fermente e se torne um vinho de onde se extrai a aguardente ou o álcool. Contudo, torna-se necessária a cultura in vivo destes microorganismos pelas usinas beneficiadoras. Nas indústrias de álcool, devido à rápida velocidade de crescimento destes

\footnotetext{
1 Estudante de Pós-graduação - Mestrado em Zootecnia - UFC - Rua: Frei Mansuetom n. 765, Varjota, CEP: 60175-070 - Fortaleza - CE. E.mail: marciograngeiro@bol.com.br

2 Professora do DZ - UFC - Av. Mister Hull, s/n - Campus do Pici. E.mail: fatima@secrel.com.br

3 Engenheiro Agrônomo do DZ - UFC - Av. Mister Hull, s/n - Campus do Pici.

4 Professor do DZ - UFC - Av. Mister Hull, s/n - Campus do Pici.

5 Professor da FAVET - UECE - Av. Dedé Brasil, 1700 - Campus do Itaperí.
} 
microorganismos, ocorre sempre excesso de produção de levedura, que pode ser usada para os mais diversos fins depois de desidratada, como por exemplo na alimentação animal.

Estudando a composição química da levedura, CAMPOS NETO (1987) verificou que a mesma contém proteínas com excelente balanço de aminoácidos essenciais, é rica em lisina e treonina e pode ser recomendada como excelente suplemento protéico em dietas baseadas em grãos de cereais.

Quanto aos minerais, a levedura apresenta um nível relativamente elevado, com variação entre $9,8 \mathrm{e}$ $14,4 \%$, sendo o potássio o principal componente desta fração. O conteúdo de gordura, ou extrato etéreo, varia com o substrato utilizado, podendo apresentar níveis de 0,9 a 1,6\%. Devido à grande riqueza em vitaminas do complexo $\mathrm{B}$, a levedura tem sido utilizada como suplemento vitamínico em dietas para monogástricos (CAMPOS NETO, 1987).

Trabalhando com dietas que continham como fonte protéica a levedura seca (Torula utilis), LATRILLE et al. (1976) verificaram que, em níveis acima de $20 \%$, ocorreu redução do ganho de peso das aves no período de 1 a 20 dias de idade.

Resultados semelhantes foram observados por PEZZATO et al. (1982a, b), que verificaram que a levedura seca de álcool constitui uma excelente alternativa para a economia de milho e soja até um nível de $20 \%$ em rações para frangos de corte.

SURDZHIISKA et al. (1987) trabalharam com níveis de substituição de 5 a $20 \%$ de levedura em dietas à base de milho e farelo de soja e $20 \%$ de substituição em dietas que continham em sua composição níveis de 3 a $5 \%$ de farinha de peixe. Os autores verificaram que a inclusão de 5 a $10 \%$ de levedura na dieta ocasionou aumento do ganho de peso das aves no período de 1 a 56 dias de idade. Porém, com a inclusão de $20 \%$, houve diminuição de 5 a $10 \%$ no ganho de peso em relação ao grupo controle e de 12 a $17 \%$, quando foi incluída farinha de peixe na dieta.

BUTOLO et al. (1997b), estudando a suplementação de rações isocalóricas e isoprotéicas com levedura de cana-de-açúcar nos níveis de 0,5 , 10 e $15 \%$, verificou que a levedura pode ser incluída até um nível de $5 \%$ e, nos níveis de 10 e $15 \%$, houve queda no desempenho dos frangos. No entanto, BUTOLO et al. (1998) afirmaram que a mesma pode ser incluída até um nível de 5\%, sem causar prejuízo no desempenho das aves, e o nível de $2,5 \%$ proporcionou os melhores resultados.

Avaliando a substituição da proteína do farelo de soja pela proteína da levedura de recuperação sobre o desempenho de frangos de corte nos níveis de 0,15 , 30 e $45 \%$, OLIVEIRA et al. (1998) verificaram melhor desempenho quando utilizaram um nível de $15 \%$ de substituição da proteína do farelo de soja pela levedura de recuperação, o que corresponde à inclusão de $5,75 \%$ na dieta.

TAMBURO et al. (1982), estudando o efeito de diferentes níveis (10, 20 e 30\%) de levedura seca de álcool sobre a umidade das excretas de frangos de corte, verificaram que, à medida que o nível de levedura seca de álcool aumentou na dieta, houve incremento na umidade das excretas.

Com base no exposto, o objetivo deste trabalho foi estudar o efeito dos diferentes níveis de inclusão da levedura de cana-de-açúcar (LCA), recuperada da indústria de aguardente de cana-de-açúcar, sobre o desempenho de frangos de corte.

\section{Material e Métodos}

Durante o período do experimento, as temperaturas máximas e mínimas foram registradas duas vezes ao dia. Ao final do experimento, foram calculadas as médias das máximas e das mínimas para todo o período. A umidade relativa também foi registrada diariamente, obtendo-se uma média ao final do experimento.

Foram utilizados 672 frangos de corte machos, da linhagem Agroceres Ross - AGROSS, com peso médio inicial de 48,5 grama, alojados com um dia de idade, por um período de 42 dias.

$\mathrm{O}$ delineamento experimental foi inteiramente casualizado, com seis tratamentos e oito repetições por tratamento. Cada repetição constava de um box com 14 aves, totalizando 112 aves por tratamento. A análise de variância foi realizada utilizando o programa estatístico SAS (1996).

A análise proximal da levedura, realizada no Laboratório de Nutrição Animal do Departamento de Zootecnia do Centro de Ciências Agrária da UFC, de acordo com a ASSOCIATION OF OFFICIAL ANALYTICAL CHEMISTS - AOAC (1990), apresentou a seguinte composição: $86,19 \%$ de matéria seca, $16,76 \%$ de proteína bruta, $2947 \mathrm{kcal} / \mathrm{kg}$ de energia metabolizável, $0,50 \%$ de extrato etéreo e $10,82 \%$ de resíduo mineral.

O cálculo das dietas foi feito utilizando um programa linear para rações de custo mínimo, SUPERCRAC (1993), que foram isocalóricas e isoprotéicas para as fases de crescimento e engorda, 
768 Rev. bras. zootec.

respectivamente (Tabelas 1 e 2), com base nas exigências nutricionais das aves estabelecidas pelo NATIONAL RESEARCH COUNCIL - NRC (1994). Estas rações foram preparadas na Fábrica de Rações do Departamento de Zootecnia do Centro de Ciências Agrárias da Universidade Federal do Ceará.

Os tratamentos foram: $\mathrm{T}_{1}=$ Dieta basal $(\mathrm{DB})$; $\mathrm{T}_{2}=\mathrm{DB}+1,5 \%$ levedura de cana-de-açúcar (LCA);

Tabela 1 - Composição percentual e valores calculados das dietas da fase inicial

Table 1 - Percentage composition and calculated values of diets in the initial phase

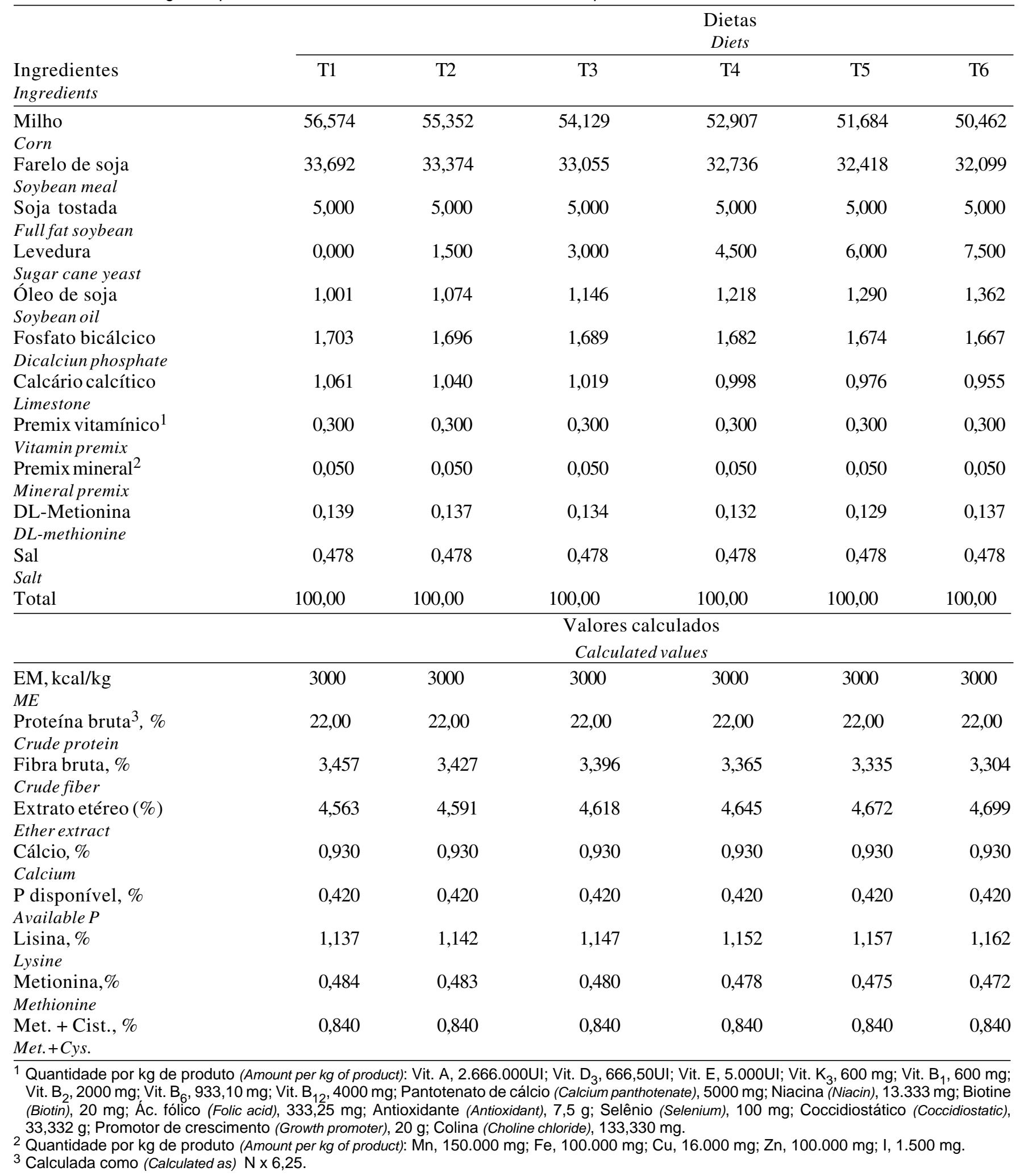


GRANGEIRO et al.

Tabela 2 - Composição percentual e valores calculados das dietas da fase de crescimento Table 2 - Percentage composition and calculated values of diets in the growing phase

\begin{tabular}{|c|c|c|c|c|c|c|}
\hline \multirow[b]{2}{*}{$\begin{array}{l}\text { Ingrediente } \\
\text { Ingredients }\end{array}$} & \multicolumn{6}{|c|}{$\begin{array}{l}\text { Dietas } \\
\text { Diets }\end{array}$} \\
\hline & $\mathrm{T} 1$ & $\mathrm{~T} 2$ & $\mathrm{~T} 3$ & $\mathrm{~T} 4$ & $\mathrm{~T} 5$ & T6 \\
\hline $\begin{array}{l}\text { Milho } \\
\text { Corn }\end{array}$ & 60,583 & 59,363 & 58,143 & 56,923 & 55,703 & 54,484 \\
\hline $\begin{array}{l}\text { Farelo de soja } \\
\text { Soybean meal }\end{array}$ & 24,224 & 23,902 & 23,580 & 23,257 & 22,935 & 22,613 \\
\hline $\begin{array}{l}\text { Soja tostada } \\
\text { Full fat soybean }\end{array}$ & 10,000 & 10,000 & 10,000 & 10,000 & 10,000 & 10,000 \\
\hline $\begin{array}{l}\text { Levedura } \\
\text { Sugar cane yeast }\end{array}$ & 0,000 & 1,500 & 3,000 & 4,500 & 6,000 & 7,500 \\
\hline $\begin{array}{l}\text { Óleo de soja } \\
\text { Soybean oil }\end{array}$ & 1,793 & 1,863 & 1,934 & 2,005 & 2,076 & 2,147 \\
\hline $\begin{array}{l}\text { Fosfato bicálcico } \\
\text { Dicalciun phosphate }\end{array}$ & 1,294 & 1,287 & 1,280 & 1,272 & 1,265 & 1,258 \\
\hline $\begin{array}{l}\text { Calcário calcítico } \\
\text { Limestone }\end{array}$ & 1,244 & 1,223 & 1,201 & 1,180 & 1,159 & 1,137 \\
\hline $\begin{array}{l}\text { Premix vitamínico } \\
\text { Vitamin premix }^{1}\end{array}$ & 0,300 & 0,300 & 0,300 & 0,300 & 0,300 & 0,300 \\
\hline $\begin{array}{l}\text { Premix mineral } \\
\text { Mineral premix }\end{array}$ & 0,050 & 0,050 & 0,050 & 0,050 & 0,050 & 0,050 \\
\hline $\begin{array}{l}\text { DL-Metionina } \\
\text { DL-Methionine }\end{array}$ & 0,135 & 0,135 & 0,135 & 0,135 & 0,134 & 0,134 \\
\hline $\begin{array}{l}\text { Sal } \\
\text { Salt }\end{array}$ & 0,377 & 0,377 & 0,377 & 0,377 & 0,377 & 0,377 \\
\hline Total & 100,00 & 100,00 & $\begin{array}{r}100,00 \\
\text { Valore } \\
\text { Calcu }\end{array}$ & $\begin{array}{l}100,00 \\
\text { udos } \\
\text { ues }\end{array}$ & 100,00 & 100,00 \\
\hline $\begin{array}{l}\mathrm{EM}, \mathrm{kcal} / \mathrm{kg} \\
M E\end{array}$ & 3150 & 3150 & 3150 & 3150 & 3150 & 3150 \\
\hline $\begin{array}{l}\text { Proteína bruta }{ }^{3}, \% \\
\text { Crude protein }\end{array}$ & 20,00 & 20,00 & 20,00 & 20,00 & 20,00 & 20,00 \\
\hline $\begin{array}{l}\text { Fibra bruta, \% } \\
\text { Crude fiber }\end{array}$ & 3,370 & 3,339 & 3,308 & 3,278 & 3,247 & 3,216 \\
\hline $\begin{array}{l}\text { Extrato etéreo }(\%) \\
\text { Ether extract }\end{array}$ & 6,147 & 6,172 & 6,198 & 6,224 & 6,250 & 6,276 \\
\hline $\begin{array}{l}\text { Cálcio, \% } \\
\text { Calcium }\end{array}$ & 0,890 & 0,890 & 0,890 & 0,890 & 0,890 & 0,890 \\
\hline $\begin{array}{l}\text { P disponível, } \% \\
\text { Available } P\end{array}$ & 0,340 & 0,340 & 0,340 & 0,340 & 0,340 & 0,340 \\
\hline $\begin{array}{l}\text { Lisina, \% } \\
\text { Lysine }\end{array}$ & 1,003 & 1,008 & 1,013 & 1,018 & 1,023 & 1,029 \\
\hline $\begin{array}{l}\text { Metionina,\% } \\
\text { Methionine }\end{array}$ & 0,370 & 0,370 & 0,370 & 0,370 & 0,370 & 0,370 \\
\hline $\begin{array}{l}\text { Met. + Cist., \% } \\
\text { Met.+Cys. }\end{array}$ & 0,718 & 0,721 & 0,723 & 0,726 & 0,727 & 0,730 \\
\hline
\end{tabular}

$\mathrm{T}_{3}=\mathrm{DB}+3,0 \% \mathrm{LCA} ; \mathrm{T}_{4}=\mathrm{DB}+4,5 \% \mathrm{LCA} ;$ $\mathrm{T}_{5}=\mathrm{DB}+6,0 \% \mathrm{LCA} ; \mathrm{T}_{6}=\mathrm{DB}+7,5 \% \mathrm{LCA}$.

Foram registrados o peso inicial no momento do alojamento dos pintos, aos 21 e 42 dias de idade. Ao final do período, foram calculados o ganho de peso médio e o cálculo do consumo de ração, este último efetuado a partir da diferença de peso observada entre a quantidade de ração fornecida no início e as sobras no final, para cada repetição. A conversão alimentar foi calculada a partir dos 
dados de consumo de ração (kg/ave) e do ganho de peso dos frangos para cada repetição.

Ao final do experimento, após um jejum de três horas, foi realizada a pesagem total das aves por box e, em seguida, retirada uma ave de cada repetição com peso semelhante à média de peso encontrada para o box para determinar o rendimento de carcaça e a porcentagem de gordura abdominal. As aves, em total de oito por tratamento, foram sacrificadas pelo método de secção da jugular sendo, então, depenadas, evisceradas, pesadas e resfriadas por 12 horas. $\mathrm{O}$ rendimento de carcaça, expresso em porcentagem, foi obtido pela relação entre o peso da carcaça eviscerada e quente e o peso vivo. A porcentagem de gordura abdominal foi obtida dividindo-se o peso da gordura abdominal retirada da carcaça pelo peso da carcaça resfriada e multiplicando-se por 100. Considerou-se a carcaça sem patas, pescoço, cabeça e vísceras.

Diariamente as aves foram observadas para o registro e diagnóstico de mortes eventuais. No final de cada fase do experimento, calculou-se o percentual de mortalidade para cada tratamento.

Aos 21 e aos 42 dias após do inicio do experimento, foi coletada uma amostra da cama, de cada box, num total de 48 amostras, sendo oito por tratamento, para determinação do teor de umidade. A análise foi realizada no Laboratório de Nutrição Animal do Departamento de Zootecnia seguindo o método da AOAC (1990).

\section{Resultados e Discussão}

A baixa qualidade protéica observada na levedura utilizada pode estar associada ao substrato do qual foi extraída, do tipo de processamento e, também, da forma de armazenamento pela indústria fornecedora da mesma. Isto pode justificar e explicar que, ao contrário da maioria dos trabalhos citados, a levedura utilizada nesta pesquisa reduziu, principalmente, a quantidade de milho adicionado nas dietas, o que a caracteriza como um ingrediente de efeito energético. Entretanto, o objetivo deste trabalho foi verificar o efeito da inclusão da levedura, e não substituir qualquer ingrediente, logo, todas as dietas foram ajustadas para atenderem as exigências nutricionais das aves, fato que pode ter colaborado para o bom desempenho dos frangos.

Os resultados de desempenho dos frangos de corte, durante o período total de 1 a 42 dias, encontram-se na Tabela 3. Nenhum efeito significativo dos níveis de inclusão de levedura de cana-de-açúcar nas dietas para frangos de corte foi verificado para as variáveis ganho de peso, consumo de ração e conversão alimentar.

LATRILLE et al. (1976), realizando experimentos com frangos de corte alimentados com dietas que continham como fonte protéica a levedura seca (Torula utilis), observaram que, em níveis acima de $20 \%$, houve redução do ganho de peso das aves no período de 1 a 20 dias de idade. Da mesma forma, SURDZHIISKA et al. (1987) verificaram que, com a inclusão de $20 \%$ de levedura (Saccharomyces cerevisiae), houve diminuição de 5 a $10 \%$ no ganho de peso em relação ao grupo controle e de 12 a 17\%, quando se adicionou farinha de peixe na dieta. Porém, com a inclusão de 5 a $10 \%$ na dieta, houve aumento do ganho de peso das aves, no período de 1 a 56 dias de idade, o que não foi observado neste trabalho.

Corroborando os resultados obtidos neste experimento, BUTOLO (1991), avaliando o valor biológico da levedura de cana-de-açúcar (Saccharomyces

Tabela 3 -Dados médios de desempenho de frangos de corte aos 42 dias de idade submetidos a dietas contendo níveis crescentes de inclusão de levedura de cana-de-açúcar

Table 3 - Performance means of the broiler chickens fed diets containing crescent levels of sugar cane yeast inclusion

\begin{tabular}{lccc}
\hline $\begin{array}{l}\text { Níveis de inclusão de levedura (\%) } \\
\text { Levels of yeast inclusion (\%) }\end{array}$ & $\begin{array}{c}\text { Ganho de peso (g/ave) } \\
\text { Weight gain (g/bird) }\end{array}$ & $\begin{array}{c}\text { Consumo de ração (g/ave) } \\
\text { Feed intake (g/bird) }\end{array}$ & $\begin{array}{c}\text { Conversão alimentar (g/g) } \\
\text { Feed conversion }(\mathrm{g} / \mathrm{g})\end{array}$ \\
\hline 0 & 2340 & 4186 & 1,79 \\
1,5 & 2313 & 4166 & 1,80 \\
3,0 & 2308 & 4224 & 1,83 \\
4,5 & 2325 & 4219 & 1,81 \\
6,0 & 2307 & 4320 & 1,87 \\
7,5 & 2308 & 4253 & 1,84 \\
F & $0,26^{\mathrm{ns}}$ & $1,71^{\mathrm{ns}}$ & $2,42^{\mathrm{ns}}$ \\
CV $(\%)$ & 3,12 & 2,78 & 3,01
\end{tabular}

ns não-significativo $(P>0,05)$.

$n s$ not significant $(P>.05)$. 
cerevisiae) proveniente das destilarias de álcool, afirmou que, com a substituição do farelo de soja pela levedura, até o nível de 10\%, nenhuma diferença significativa foi verificada para o ganho de peso de frangos de corte.

Contudo, BUTOLO et al. (1997a) afirmaram que a levedura poderia ser utilizada até o nível de $5 \%$ e, em níveis mais elevados (10 e 15\%), houve queda de desempenho dos frangos, o que poderia estar associado à pior digestibilidade da parede celular, que reduz a biodisponibilidade dos nutrientes. Porém, em 1998, BUTOLO et al., também concluíram ser possível a utilização de levedura em nível de até $5 \%$ na dieta de frango, mas o nível de inclusão de $2,5 \%$ foi o que proporcionou o melhor desempenho. Os níveis recomendados por estes autores estão abaixo dos valores encontrados no presente estudo.

O consumo voluntário de ração em monogástricos, segundo ESPÍNDOLA et al. (1995), está dentro de certos limites, regulado pelo nível de energia da dieta, assumindo que a mesma contenha níveis adequados de nutrientes essenciais. Nesse experimento, todas as dietas foram isocalóricas e isoprotéicas, fato que pode ser considerado determinante da ausência de diferença significativa entre os tratamentos, nas diferentes fases experimentais.

Concordando com os resultados obtidos neste experimento, LATRILLE et al. (1976), trabalhando com levedura seca (Torula utilis); SAMANTA e MONDAL (1988), com levedura seca de álcool; OLIVEIRA et al. (1998), com levedura de recuperação, também não registraram efeito significativo do uso de levedura sobre o consumo de ração de frangos de corte.

BUTOLO et al. (1997b) encontraram efeito quadrático para o consumo de ração, quando usaram níveis de 0 a $15 \%$ de levedura de cana-de-açúcar, em dietas para frangos de corte no período de 36 a 42 dias. BUTOLO et al. (1998) também verificaram resposta quadrática para o consumo de ração de frangos de corte, que receberam dietas contendo níveis de 0 a 7,5\% de levedura de cana-de-açúcar em sua composição.

De acordo com WALDROUP et al. (1971), a maioria dos problemas não nutricionais, relacionados com uso de proteína microbiana, diz respeito à palatabilidade. Embora possa variar com a espécie, elevado nível de levedura na ração pode diminuir a palatabilidade, principalmente devido à pulverulência.

Nesta pesquisa, como o nível de levedura utilizado foi de até $7,5 \%$, e na formulação das dietas foram usados óleo e soja integral, as rações apresentaram boa densidade, não havendo, portanto, efeito no consumo.

LATRILLE et al. (1976), realizando experimentos com frangos de corte de 1 a 28 dias de idade e utilizando dietas que continham como fonte protéica a levedura seca (Torula utilis), registraram pior conversão alimentar quando o nível de inclusão de levedura na dieta foi de $25 \%$ ou mais. Porém, SURDZHIISKA et al. (1987), utilizando níveis de inclusão de levedura que variavam de 5 a $10 \%$, não encontraram qualquer efeito significativo sobre a conversão alimentar de frangos de corte no período de 1 a 56 dias, concordando com os resultados encontrados neste experimento.

PEZZATO et al. (1982a), usando níveis de inclusão de levedura de até $30 \%$, em dietas para frangos de corte, verificaram que a melhor conversão alimentar foi apresentada pelos frangos que consumiram dietas com níveis de até $10 \%$ de levedura de cana-deaçúcar. Em outro estudo, PEZZATO et al. (1982b) não encontraram efeito sobre a conversão alimentar, quando houve a inclusão de minerais em teores equivalentes ao fornecido por $20 \%$ de levedura seca de álcool nas dietas.

Os dados obtidos neste trabalho discordam daqueles observados por BUTOLO et al. (1997a e 1998), que em seus estudos verificaram resposta quadrática e linear crescente, respectivamente, sobre a conversão alimentar, quando a levedura de cana-de-açúcar foi incluída em níveis crescentes nas dietas de frangos de corte, no período de 1 a 42 dias de idade. Estes resultados diferem também daqueles obtidos por OLIVEIRA et al. (1998), que, utilizando níveis de substituição da proteína do farelo de soja pela proteína da levedura de recuperação até $45 \%$, constataram que a conversão alimentar dos frangos piorou linearmente com o aumento da substituição do farelo de soja pela levedura de recuperação.

As diferenças verificadas nos resultados de conversão alimentar apresentados por alguns autores e os dados obtidos neste trabalho podem estar associadas à utilização de níveis mais elevados e, também, à espécie de levedura usada por aqueles autores.

Nenhum efeito significativo sobre o rendimento de carcaça e a porcentagem de gordura abdominal foi observado neste experimento, quando níveis crescentes de levedura de cana-de-açúcar foram adicionados às dietas experimentais (Tabela 4).

Os valores obtidos para gordura abdominal neste experimento situaram-se entre 1,59 e $2,23 \%$ da carcaça resfriada e podem ser considerados dentro da 
772 Rev. bras. zootec.

média apresentada pelo frango atual, que é de 2,0\%, segundo MENDES (1992). O teor de gordura abdominal apresenta alta correlação com o teor de gordura total da carcaça. Em virtude da exigência atual do consumidor, a obtenção de carcaça mais magra tem sido uma preocupação constante nos programas de melhoramento genético avícola.

A mortalidade registrada durante as fases inicial e de engorda foi de 5,89 e $1,04 \%$, respectivamente. Estes valores se encontram dentro dos limites aceitáveis para a linhagem utilizada. De acordo com as necrópsias feitas das aves, pode-se afirmar que as mortes ocorridas não foram devidas ao uso de levedura de cana-de-açúcar nas dietas, e sim a outras causas como onfalite e morte súbita, na sua maioria.

A umidade da cama, medida ao final do período inicial com 21 dias e ao final do período de crescimento com 42 dias de idade, não foi afetada pelos níveis crescentes de inclusão de levedura de cana-deaçúcar (Tabela 5).

A utilização de níveis crescentes de levedura seca em dietas para frangos de corte, em estudos feitos por LATRILLE et al. (1976), mostraram que a inclusão de $20 \%$ de levedura seca nas dietas resultou em aspecto pegajoso às fezes.

TAMBURO et al. (1982), estudando o efeito da adição de diferentes níveis $(0,10,20$, e $30 \%)$ de levedura seca de álcool de cana-de-açúcar sobre a umidade das excretas de frangos de corte, registraram também incremento na umidade das excretas, à medida que aumentou o nível de levedura seca de álcool na dieta. Estes resultados discordam dos obtidos neste experimento, o que, talvez, se deve ao uso de mais baixos níveis de levedura de cana-de-açúcar na dieta.

Tabela 4 - Características de carcaça de frangos de corte, submetidos a dietas contendo níveis crescentes de inclusão de levedura de cana-de-açúcar

Table 4 - Carcass caracteristics of broiler chickens fed diets containing crescent levels of sugar cane yeast inclusion

\begin{tabular}{lcc}
\hline $\begin{array}{l}\text { Níveis de inclusão da levedura }(\%) \\
\text { Levels of yeast inclusion }(\%)\end{array}$ & $\begin{array}{c}\text { Rendimento de carcaça } \\
(\% \text { do peso vivo) } \\
\text { Carcass yield (\% body weight) }\end{array}$ & $\begin{array}{c}\text { Gordura abdominal } \\
\text { \% da carcaça resfriada) } \\
\text { Abdominal fat }(\% \text { cold carcass) }\end{array}$ \\
\hline 0 & 73,69 & 1,59 \\
1,5 & 73,24 & 2,01 \\
3,0 & 74,75 & 1,92 \\
4,5 & 73,88 & 2,02 \\
6,0 & 73,77 & 1,94 \\
7,5 & 75,04 & 2,23 \\
F & $1,72^{\mathrm{ns}}$ & $0,97^{\mathrm{ns}}$ \\
$\mathrm{CV}(\%)$ & 2,00 & 30,77
\end{tabular}

ns: não-significativo $(P>0,05)$

ns: not significant $(P>05)$.

Tabela 5 - Umidade da cama (\%) de frangos de corte, submetidos a dietas contendo níveis crescentes de inclusão de levedura de cana-de-açúcar

Table 5 - Broiler litter humidity of broiler chickens fed diets containing crescent levels of sugar cane yeast inclusion

\begin{tabular}{lcc}
\hline $\begin{array}{l}\text { Níveis de inclusão da levedura (\%) } \\
\text { Levels of yeast inclusion (\%) }\end{array}$ & Aos 21 dias & Aos 42 dias \\
At 42 days
\end{tabular}

ns: não-significativa $(P>0,05)$.

ns: not significant $(P>05)$. 


\section{Conclusões}

A levedura de cana-de-açúcar pode ser usada em níveis de até 7,5\%, em dietas de frangos de corte, sem afetar significativamente o desempenho zootécnico, as características de carcaça e teor de umidade da cama.

\section{Referências Bibliográficas}

ASSOCIATION OF OFFICIAL ANALYTICAL CHEMISTS AOAC. 1990. Official methods of analysis. 15.ed. Arlington, Virginia. v.1. 1298p.

BUTOLO, E.A.F., NOBRE, P.T.C., BUTOLO, J.E. Determinação do valor energético e nutritivo da levedura de cana-deaçúcar (Saccharomyces cerevisiae) para frangos de corte. In: CONFERÊNCIA APINCO' 1997 DE CIÊNCIA E TECNOLOGIA AVÍCOLAS, 1997, Campinas. Trabalhos ... Campinas, SP: FACTA/WSPA-BR, 1997. p.11.

BUTOLO, J.E. Avaliação biológica da levedura de cana (Saccharomyces cerevisiae) na alimentação de frangos de corte, fase inicial e engorda, substituindo-se total e parcialmente a suplementação de vitaminas do complexo B, presentes na levedura de cana. In: SEMINÁRIO DE PRODUÇÃO E COMERCIALIZAÇÃO DE LEVEDURA DE CANA, 2, 1991, Piracicaba. Anais... Piracicaba, SP: CTC, 1991. p.47

BUTOLO, J.E., NOBRE, P.T.C., BUTOLO E.A.F. et al. Utilização da levedura de cana-de-açúcar (Saccharomyces cerevisiae) em dietas de frangos de corte. In: CONFERÊNCIA APINCO' 1997 DE CIÊNCIA E TECNOLOGIA AVÍCOLAS, 1997a, Campinas, SP. Trabalhos ... Campinas, SP: FACTA/WSPA-BR, 1997. p.29.

BUTOLO, J.E., BUTOLO E.A.F., NOBRE, P.T.C. et al. Utilização da levedura de cana-de-açúcar (Saccharomyces cerevisiae) na performance de frangos de cortes - Fase II. In: CONFERÊNCIA APINCO' 1998 DE CIÊNCIA E TECNOLOGIA AVÍCOLAS, 1998, Campinas, SP. Trabalhos... Campinas, SP: FACTA/WSPA-BR, 1998. p.41.

CAMPOS NETO, O. Utilização dos subprodutos da indústria sucroalcooleira na alimentação animal. In: SIMPÓSIO SOBRE PRODUÇÃO ANIMAL, 4, 1987, Brasília, DF. Anais... Brasília, DF: SBZ, 1987. p.129-152.

ESPÍNDOLA, G.B., FUENTES, M.F.F., GUERREIRO, M.E.F. et al. Avaliação da energia digestível em dietas para coelhos. In: REUNIÃO ANUAL DA SOCIEDADE BRASILEIRA DEZOOTECNIA, 32, 1995, Brasília. Anais... Brasília: SBZ, 1995. p.396-398.

LATRILLE, L.L., RIQUELM, G.C., MANTEROLA, H.B. et al. 1976. Evaluación de dos tipos de leveduras (Torula utilis y Saccaromyces cerevisiae sp), como fuente proteica para raiciones de pollos em crescimento. Avances en Produción Animal, (1):45-51.

MENDES, A.A. 1992. Características de interesse industrial das principais linhagens de frangos de corte criadas no Brasil. In: INDUSTRIALIZAÇÃO DA CARNE DE FRANGO. Campinas, SP: Centro de Tecnologia de Carne/ITAL. p.1-21.

NATIONAL RESEARCH COUNCIL - NRC. 1994. Nutrient requirements of poultry. 9. ed. rev. Washington: National Academy Press. 155p.

OLIVEIRA, P.B., GARCIA, E.R.M., OVIEDO R.E.O. et al. Substituição da proteína do farelo de soja pela proteína da levedura de recuperação nas rações, sobre o desempenho de frangos. In: REUNIÃO ANUAL DA SOCIEDADE BRASILEIRA DE ZOOTECNIA, 35, 1998, Botucatu, SP. Anais... Botucatu, SP: SBZ, 1998. p.404.

PEZZATO, L.E., POLANO, S.A., SAUCEDO, E.C.A. et al. Levedura seca (Saccharomyces cerevisiae) de álcool de canade-açúcar na alimentação de frangos de corte. In: REUNIÃO ANUAL DA SOCIEDADE BRASILEIRA DE ZOOTECNIA, 19, 1982, Piracicaba, SP. Anais... Piracicaba, SP: SBZ, 1982a. p.25.

PEZZATO, A.C., PIAI JR., A., SUZUKI, C.A.T. et al. Adição de minerais em ração para frangos de corte, contendo levedura seca de álcool (LSA). In: REUNIÃO ANUAL DA SOCIEDADE BRASILEIRA DE ZOOTECNIA, 19, 1982, Piracicaba, SP. Anais... Piracicaba, SP: SBZ, 1982b. p. 25.

PINOTTI, F.R. Situação atual e perspectivas da produção da indústria sucro-alcooleira: levedura. In: SIMPÓSIO SOBRE TECNOLOGIA DA PRODUÇÃO E UTILIZAÇÃO DA LEVEDURA DESIDRATADA NA ALIMENTAÇÃO ANIMAL, 1997, Campinas, SP. Anais... Campinas, SP: Colégio Brasileiro de Nutrição Animal (CBNA), 1997. p.1-6.

SAMANTA, G., MONDAL, L. 1988. Feeding value of industrial yeast by-product in broiler diets. Ind. J. Poult. Sci., 23(1):99-100.

SAMPAIO, I.B.M. 1998. Estatística aplicada à experimentação animal. Belo Horizonte: Fundação de Ensino e Pesquisa em Medicina Veterinária e Zootecnia. 221p.

SAS INSTITUTE INC. 1996. SAS User's guide: statistics, version 6.12, SAS Institute Inc., Carry, NC.

SUPERCRAC. Ração de custo mínimo. Versão 1.02 Windows. TD software. 1993.

SURDZHIISKA, S., MARINOV, B., TOMOVA, D. 1987. Mixed feeds for broiler chickens with different amounts of fodder yeast. Zhivotnov" dni Nauki, 24(1):47-52.

TAMBURO, M.E., GINTERS, K.M., LUCHESE, L. et al. Efeito da adição de diferentes níveis de levedura seca (Saccharomyces cerevisiae) de álcool de cana-de-açúcar, sobre a umidade das excretas de frangos de corte. In: REUNIÃO ANUAL DA SOCIEDADE BRASILEIRA DE ZOOTECNIA, 19, 1982, Piracicaba, SP. Anais... Piracicaba, SP: SBZ, 1982. p.26.

WALDROUP, P.J., HILLARD, C.A., MITCHELL, R.J. 1971. The nutritive value of yeast grown on hydrocarborn fractions for broiler chicks. Poult. Sci., 50(4):1022-1029.

Recebido em: $11 / 07 / 00$ Aceito em: 18/01/01 